\title{
Higher steroid sulfation is linked to successful weight loss in obese children
}

\author{
Thomas Reinehrr, ${ }^{1,}$, Alberto Sánchez-Guijo ${ }^{2, *}$, Nina Lass ${ }^{1}$ and Stefan A Wudy \\ 'Department of Pediatric Endocrinology, Diabetes and Nutrition Medicine, Vestische Hospital for Children and Adolescents Datteln, University of \\ Witten/Herdecke, Witten, Germany \\ ${ }^{2}$ Steroid Research \& Mass Spectrometry Unit, Division of Pediatric Endocrinology and Diabetology, Center of Child and Adolescent Medicine, \\ Justus-Liebig-University Giessen, Giessen, Germany \\ Correspondence should be addressed to T Reinehr: T.Reinehr@kinderklinik-datteln.de \\ *(T Reinehr and A Sánchez-Guijo contributed equally to this work)
}

\begin{abstract}
Objective: Little information is available on the steroid sulfates profile in obese children. Therefore, we examined whether sulfated steroids are linked with weight status and associated comorbidities in obese children.

Methods: We analyzed 66 obese children (mean age $10.5 \pm 2.5$ years, $57.6 \%$ female, $53.9 \%$ prepubertal, mean BMI $27.0 \pm 4.6 \mathrm{~kg} / \mathrm{m}^{2}, 50 \%$ with BMI-SDS reduction $>0.5,50 \%$ without BMI-SDS reduction) who participated in an outpatient 1-year intervention program based on exercise, behavior and nutrition therapy. We measured intact sulfated steroids (cholesterol sulfate (CS), pregnenolone sulfate (PregS), $17 \alpha \mathrm{OH}$ pregnenolone sulfate (170H-PregS), $16 \alpha \mathrm{OH}$ dehydroepiandrosterone sulfate (16OH-DHEAS), DHEAS, androstenediol-3-sulfate, androsterone sulfate and epiandrosterone sulfate) by LC-MS/MS, and insulin resistance index HOMA, lipids, blood pressure at baseline and 1 year later. Results: All sulfated steroids except 170H-PregS, 16OH-DHEAS, androsterone sulfate and epiandrosterone sulfate were higher in boys compared to girls. Concentrations of CS before intervention were higher in children who lost weight. After 1 year of treatment, both groups showed increased levels of DHEAS, 16OH-DHEAS and androstenediol3-sulfate, but PregS was only increased in children with weight loss. None of the steroid sulfates was significantly related to cardiovascular risk factors or HOMA except $170 \mathrm{H}-P r e g S$, which was associated with systolic blood pressure both in cross-sectional ( $\beta$-coefficient: $0.09 \pm 0.07, P=0.020$ ) and longitudinal analyses ( $\beta$-coefficient: $0.06 \pm 0.04$, $P=0.013$ ) in multiple linear regression analyses.

Conclusions: Since higher steroid sulfation capacity was associated with successful weight intervention in children disruption of sulfation may be associated with difficulties to lose weight. Future studies are necessary to prove this hypothesis.
\end{abstract}
Key Words
- lifestyle intervention
- weight loss
- sulfated steroids
- cholesterol sulfate
- children

Endocrine Connections (2018) 7, 1020-1030

\section{Introduction}

Obesity is a complex condition associated with changes in many steroid hormones also including androgens: concentrations of testosterone and DHEAS and their precursors are increased in children $(1,2)$ and obese women (3), while obese men demonstrated decreased testosterone levels (4). Interestingly, obese women with increased androgens and obese men with low testosterone concentrations are more prone to metabolic disturbances such as insulin resistance, type 2 diabetes mellitus, lipid abnormalities and hypertension and may therefore be at particular risk of developing atherosclerotic complications $(2,5,6,7,8,9)$. Furthermore, increased androgens are

$$
\begin{array}{lr}
\text { https://ec.bioscientifica.com } & \text { ○ } 2018 \text { The authors } \\
\text { https://doi.org/10.1530/EC-18-0233 } & \text { Published by Bioscientifica Ltd }
\end{array}
$$

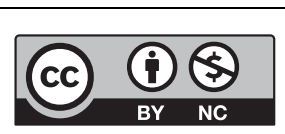

This work is licensed under a Creative Commons Attribution-NonCommercial 4.0 International License. 
related to polycystic ovarian syndrome (PCOS) in females $(7,10)$. In children, a high androgenic activity is discussed to be associated with precocious puberty, premature adrenarche and accelerated bone age with relatively tall stature $(11,12)$.

Of importance, the great majorities of studies analyzed unconjugated steroids, but recent research suggests that also sulfated steroids may be involved in these processes linking steroids to comorbidities of obesity. For example, a relationship between the concentration of sulfated steroids and glucose tolerance has been reported in mice (13). Sulfated steroids are the most abundant fraction of steroids in human blood. Sulfated steroids are originally synthesized from the unconjugated steroid by sulfation. This reaction, which belongs to phase II metabolism, requires the action of steroid sulfotransferases (SULTs) (14). Disruption of sulfation due to inactivating mutations in the human gene encoding PAPSS2, a crucial cofactor of sulfotransferases, has been shown to result in increased androgen activation and PCOS phenotype in both homozygous and heterozygous individuals $(15,16)$.

Sulfated steroids cannot interact directly with steroid receptors (17). However, there is growing evidence suggesting that sulfated steroids can access different tissues of the human body by circulation and transport into cells, where they can be activated by the action of steroid sulfatase (STS) (18). In absolute STS deficiency (STSD), most sulfated steroids in serum are elevated compared to healthy controls (19). STS is not the only enzyme that exhibits sulfatase activity for sulfated steroids, at least in vitro. Recently, we reported that $3 \beta$-hydroxysteroid dehydrogenase type 2 (3 $\beta$ HSD2) can cleave the sulfate group of some sulfated steroids to produce unconjugated steroids, i.e. PregS produced progesterone and androstenedione was synthesized from DHEAS (19).

As only sparse data exist on the sulfates of androgens and their precursors in children, we analyzed intact sulfated steroids using state-of-the-art liquid chromatographytandem mass spectrometry (LC-MS/MS) (20). This method can quantify 11 sulfated steroids simultaneously, providing a powerful tool to understand the sulfated steroidome in human blood (21). We hypothesized that sulfated steroids concentrations are linked with weight status in obese children since substantial weight loss in obese children is associated with variations of unconjugated steroids like androgens and corticoids (1, 2, 6). In addition, we analyzed whether cardiovascular risk factors linked to obesity, including insulin resistance, are associated with steroid sulfates.

\section{Subjects and methods}

\section{Subjects}

Written informed consent was obtained from all children and their parents. The study was approved by the Local Ethics Committee of the University of Witten/Herdecke in Germany.

We examined 66 obese Caucasian children (mean age $10.5 \pm 2.5$ years, $57.6 \%$ female, $53.9 \%$ prepubertal, mean BMI $27.0 \pm 4.6 \mathrm{~kg} / \mathrm{m}^{2}$ ). We choose 33 children with substantial BMI-SDS reduction of $>0.5$ and 33 age-, gender- and pubertal stage-matched children without BMI-SDS reduction. This classification was used because a reduction of $>0.5$ SDS-BMI leads to an improvement of insulin resistance as well as cardiovascular risk factors and normalized hormones like leptin, cortisol or adiponectin $(6,22,23,24)$.

All children participated in the lifestyle intervention 'Obeldicks', which has been described in detail elsewhere (25). Briefly, this outpatient intervention program for obese children is based on physical exercise, nutrition education and behavior therapy including the individual psychological care of the child and his or her family. The nutritional course is based on a fat and sugar-reduced diet as compared to the every-day nutrition of German children.

\section{Exclusion criteria}

None of the children in the current study suffered from endocrine disorders, premature adrenarche or syndromal obesity. None of the obese children entered into puberty during the study period.

\section{Measurements}

We analyzed BMI, blood pressure (BP), lipids, the insulin resistance index HOMA and sulfated steroids in children (cholesterol sulfate (CS), pregnenolone sulfate (PregS), 17OH-PregS, DHEAS, 16OH-DHEAS, androstenediol3-sulfate (A-3-S), androsterone sulfate (AS) and epiandrosterone sulfate (ES)) at baseline and at the end of the 1-year lifestyle intervention 'Obeldicks'.

Height was measured to the nearest centimeter using a rigid stadiometer. Weight was measured unclothed to the nearest $0.1 \mathrm{~kg}$ using a calibrated balance scale. BMI was calculated as weight in kilograms $(\mathrm{kg})$ divided by the square of height in meters $\left(\mathrm{m}^{2}\right)$. The degree of overweight was quantified using Cole's least mean square method,

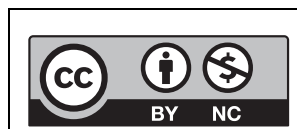

This work is licensed under a Creative Commons Attribution-NonCommercial 4.0 International License. 
which normalized the BMI skewed distribution and expressed BMI as a standard deviation score (BMI-SDS) (26). Reference data for German children were used (27). All children in the study were obese according to the definition of the International Obesity Task Force (28).

Pubertal stage was determined by well-trained physicians according to Marshall and Tanner. Pubertal developmental stage was categorized into two groups based on breast and genital stages (prepubertal: boys with genital stage I, girls with breast stage I, pubertal: boys with genital stage $\geq$ II; girls with breast stage $\geq$ II).

BP was measured using a validated protocol (29). Systolic and diastolic BP were measured at the right arm twice after a 10-min rest in the supine position by using a calibrated sphygmomanometer and averaged. The cuff size was based on the length and circumference of the upper arm and was as large as possible without having the elbow skin crease obstructing the stethoscope (29). The intra- and inter-operator variability was $<5 \%$ for systolic and diastolic BP.

Blood sampling was performed in the fasting state at 08:00 h After clotting, blood samples were centrifuged for $10 \mathrm{~min}$ at $5150 \mathrm{~g}$. Serum was stored at $-81^{\circ} \mathrm{C}$ for later determination of steroid hormones sulfates and insulin. All samples were thawed only once. Serum triglyceride, high-density lipoprotein (HDL) cholesterol, low-density lipoprotein (LDL) cholesterol and total cholesterol concentrations were measured using commercially available test kits (LDL-C- and HDL-C-Plus, Roche Diagnostics; Vitros analyzer, Ortho Clinical Diagnostics, Neckargemuend, Germany; MEIA, Abbott). Intra- and inter-assay variations for the concentrations $(\mathrm{CV})$ of these variables were less than 5\%. Insulin concentrations were measured by microparticle enhanced immunometric assay (MEIA, Abbott). Glucose levels were determined by colorimetric test using a Vitros analyzer (Ortho Clinical Diagnostics). Homeostasis model assessment (HOMA) was used to detect the degree of insulin resistance using the formula: resistance $(\mathrm{HOMA})=($ insulin $(\mathrm{mU} / \mathrm{L}) \times$ glucose $(\mathrm{mmol} / \mathrm{L})) / 22.5(30)$.

Measurement of steroid sulfates by mass spectrometry was performed as previously described in detail (21). Briefly, $300 \mu \mathrm{L}$ of each serum sample were incubated during $15 \mathrm{~min}$ with a mix of internal standards $(50 \mu \mathrm{L})$. All internal standards had a concentration of $1 \mu \mathrm{g} / \mathrm{mL}$, with the exception of CS, which was $6 \mu \mathrm{g} / \mathrm{mL}$. Next, $1 \mathrm{~mL}$ of acetonitrile- $\mathrm{ZnSO}_{4}(89 \mathrm{~g} / \mathrm{L}, 4: 1$ (v/v)) was added to precipitate the proteins and the mixture was incubated again for $15 \mathrm{~min}$. After incubation, the samples were centrifuged for $10 \mathrm{~min}$ at $14,500 \mathrm{~g}$.
The supernatant was collected in a glass tube and $3 \mathrm{~mL}$ of water were added. Solid phase extraction of the samples was performed with SepPak C18 cartridges, which were conditioned with $2 \mathrm{~mL}$ of methanol followed by $2 \mathrm{~mL}$ of water. Each sample was loaded onto the cartridge and washed with different solvents: first $3 \mathrm{~mL}$ of water, followed by $3 \mathrm{~mL}$ of hexane, $4 \mathrm{~mL}$ of chloroform and $4 \mathrm{~mL}$ of methanol. Sulfated steroids were eluted with the methanolic fraction. This final fraction was evaporated with nitrogen at $40^{\circ} \mathrm{C}$ and reconstituted with $250 \mu \mathrm{L}$ of a solution of $79.75 \%$ water, $10 \% \mathrm{MeOH}$, $10 \%$ acetonitrile and $0.25 \%$ ammonium hydroxide. Finally, each reconstitution solution was centrifuged and $10 \mu \mathrm{L}$ were injected in the LC-MS/MS system. Liquid chromatography was performed with a Accucore Phenyl-X column $(100 \times 2.1 \mathrm{~mm}, 2.6 \mu \mathrm{m})$ from Thermo Fisher Scientific, connected to a HPLC system (Agilent 1200SL). MS/MS quantification was performed with a triple quadrupole mass spectrometer (TSQ, Quantum Ultra; Thermo Fisher Scientific).

\section{Statistics}

Statistical analyses were performed using the Winstat software package (R. Fitch Software, Bad Krozingen, Germany). Normal distribution was tested by the Kolmogorov-Smirnov test. Changes of steroid hormone sulfates in the 1-year follow-up were correlated to changes of insulin, HOMA, lipids and changes of BP by Spearman correlation. To compare variables at baseline or in the course of 1 year, Fisher exact test and Student's $t$-test for paired and unpaired observations, Wilcoxon and MannWhitney $U$ test were used as appropriate. In all significant associations in univariate correlation analyses, backward multiple linear regression analyses were performed adjusted for age, gender, pubertal stage and degree of overweight at baseline as well as changes of BMI-SDS and pubertal stage in longitudinal analyses.

A $P$-value $<0.05$ was considered as significant. Data were presented as mean and standard deviation for normally distributed variables and median and interquartile range (IQR) for not normally distributed variables.

\section{Results}

All sulfated steroids except CS were significantly associated to age (Table 1). Furthermore, we found significant correlations between the concentrations of some sulfated steroids (Table 2). 
Table 1 Associations between steroid sulfates and anthropometrics and cardiovascular risk factors at baseline (Spearman correlation)

\begin{tabular}{l}
\hline \\
\hline Age \\
BMI \\
Systolic blood pressure \\
Diastolic blood pressure \\
Fasting glucose \\
HOMA \\
Cholesterol \\
HDL-cholesterol \\
LDL-cholesterol \\
Triglycerides
\end{tabular}

\begin{tabular}{l}
\multicolumn{1}{c}{ CS } \\
\hline 0.07 \\
0.05 \\
0.19 \\
0.05 \\
-0.02 \\
-0.09 \\
$0.52 * * *$ \\
0.10 \\
$0.45^{* * *}$ \\
$0.25^{*}$ \\
\hline
\end{tabular}

\begin{tabular}{|c|c|}
\hline PregS & 17 $\alpha \mathrm{OH}$ PregS \\
\hline $0.22 *$ & $0.24 *$ \\
\hline 0.19 & 0.16 \\
\hline 0.19 & $0.27 *$ \\
\hline 0.07 & 0.08 \\
\hline 0.21 & 0.16 \\
\hline $0.28 *$ & $0.29 * *$ \\
\hline 0.03 & 0.06 \\
\hline 0.05 & -0.02 \\
\hline 0.13 & 0.15 \\
\hline-0.18 & -0.11 \\
\hline
\end{tabular}

\begin{tabular}{l}
\hline $\mathbf{1 6 \alpha O H}$ DHEAS \\
\hline $0.43^{* * *}$ \\
$0.31 * *$ \\
0.15 \\
0.19 \\
$0.26^{*}$ \\
$0.42^{* * *}$ \\
$-0.24^{*}$ \\
-0.06 \\
-0.17 \\
$-0.24^{*}$ \\
\hline
\end{tabular}

\begin{tabular}{l}
\hline DHEAS \\
\hline $0.63^{* * *}$ \\
$0.51 * * *$ \\
0.16 \\
$0.23^{*}$ \\
$0.25^{*}$ \\
$0.30^{* *}$ \\
-0.13 \\
0.02 \\
-0.04 \\
$-0.28 *$ \\
\hline
\end{tabular}

\begin{tabular}{l}
\hline $\mathbf{A - 3 - S}$ \\
\hline $0.55^{* * *}$ \\
$0.49^{* * *}$ \\
$0.23^{*}$ \\
0.16 \\
$0.26^{*}$ \\
$0.28^{* *}$ \\
-0.07 \\
0.02 \\
0.01 \\
$-0.26^{*}$ \\
\hline
\end{tabular}

\begin{tabular}{l}
\hline \multicolumn{1}{c}{ AS } \\
\hline $0.46 * * *$ \\
$0.38^{* * *}$ \\
0.15 \\
$0.29 * *$ \\
0.10 \\
$0.21 *$ \\
$-0.25^{\star}$ \\
-0.03 \\
-0.19 \\
-0.10 \\
\hline
\end{tabular}

\begin{tabular}{l}
\hline \multicolumn{1}{c}{ ES } \\
\hline $0.54^{* * *}$ \\
$0.44^{* * *}$ \\
$0.22^{*}$ \\
$0.32^{* *}$ \\
0.18 \\
$0.29^{* *}$ \\
$-0.22^{*}$ \\
-0.06 \\
-0.17 \\
-0.11 \\
\hline
\end{tabular}

$* P<0.05 ; * * P<0.01 ; * * * P<0.001$.

A-3-S, androstenediol-3-sulfate; AS, androsterone sulfate; CS, cholesterol sulfate; DHEAS, dehydroepiandrosterone sulfate; ES, epiandrosterone sulfate; HDL, high-density lipoprotein; LDL, low density lipoprotein; PregS, pregnenolone sulfate.

Comparing boys and girls who did not differ significantly in their pubertal stage, we demonstrated that CS, DHEAS and A-3-S concentrations were significantly higher in boys, while 17OH-PregS, 16OH-DHEAS, AS and ES did not present significant differences (Table 3).

DHEAS, 16OH-DHEAS, A-3-S and ES were significantly higher in pubertal children, while CS, PregS and $17 \mathrm{OH}$-PregS had no significant differences between prepubertal and pubertal children (Table 4).

All steroid sulfates increased significantly in the observation period with independence of change of weight status, with the exception of CS and 17OH-PregS. CS levels before intervention were higher in children with substantial weight loss (Table 5). After 1-year intervention, PregS concentrations increased only in children with substantial decrease of BMI-SDS (Table 5). In addition, the increase of DHEAS was higher in children with substantial weight loss compared to the children without substantial decrease of BMI-SDS (Table 5).

Analysis of only prepubertal children, who remained prepubertal in the 1-year intervention period, demonstrated the same findings with one exception
(Table 6): 17OH-PregS decreased in the children with substantial weight loss and increased in the children without substantial weight loss.

CS was significantly and positively associated with cholesterol and triglycerides both at baseline as well as to changes of overweight in the 1-year follow-up period (Tables 1 and 7). A-3-S was significantly positively associated with baseline BMI and HOMA both crosssectionally and longitudinally. 17OH-PregS were significantly positively associated with systolic BP both at baseline as well as to its changes in the 1-year follow-up period. There were no further significant correlations between steroid hormone sulfates and anthropometrics, lipids or BP that were present in both cross-sectional and longitudinal analyses.

In multiple linear regression analyses adjusted to age, gender and pubertal stage, baseline 17OH-PregS significantly associated with baseline systolic BP ( $\beta$-coefficient $0.09 \pm 0.07 ; P=0.020$ ), and baseline $16 \alpha \mathrm{OH}$ DHEAS was significantly associated with baseline HOMA ( $\beta$-coefficient $6.1 \pm 6.0 ; \quad P=0.049$ ), while no further significant associations could be observed.

Table 2 Associations between steroid sulfates at baseline (Spearman correlation).

\begin{tabular}{|c|c|}
\hline & CS \\
\hline CS & - \\
\hline Pregs & -0.04 \\
\hline $17 \alpha \mathrm{OH}$ Pregs & 0.11 \\
\hline $16 \alpha \mathrm{OH}$ DHEAS & -0.13 \\
\hline DHEAS & 0.01 \\
\hline A-3-S & 0.02 \\
\hline AS & -0.10 \\
\hline ES & -0.09 \\
\hline
\end{tabular}

\begin{tabular}{|c|c|}
\hline PregS & $17 \alpha$ OH PregS \\
\hline-0.04 & 0.11 \\
\hline- & $0.84 * * *$ \\
\hline $0.84 * * *$ & - \\
\hline 0.37 ** & $0.42 * * *$ \\
\hline $0.53 * * *$ & $0.55 * * *$ \\
\hline $0.52 * * *$ & $0.50 * * *$ \\
\hline 0.08 & 0.16 \\
\hline 0.18 & $0.25 *$ \\
\hline
\end{tabular}

\begin{tabular}{c}
$16 \alpha$ OH DHEAS \\
\hline-0.13 \\
$0.37 * *$ \\
$0.42 * * *$ \\
- \\
$0.70 * * *$ \\
$0.61 * * *$ \\
$0.54 * * *$ \\
$0.58 * * *$ \\
\hline
\end{tabular}

\begin{tabular}{l}
\hline DHEAS \\
\hline 0.01 \\
$0.53 * * *$ \\
$0.55 * * *$ \\
$0.70 * * *$ \\
- \\
$0.91 * * *$ \\
$0.54 * * *$ \\
$0.91 * * *$ \\
\hline
\end{tabular}

\begin{tabular}{c}
\hline A-3-S \\
\hline 0.02 \\
$0.52 * * *$ \\
$0.50 * * *$ \\
$0.61 * * *$ \\
$0.91 * * *$ \\
- \\
$0.41 * * *$ \\
$0.46 * * *$ \\
\hline
\end{tabular}

\begin{tabular}{c}
\hline AS \\
\hline-0.10 \\
0.08 \\
0.16 \\
$0.54 * * *$ \\
$0.54 * * *$ \\
$0.41 * * *$ \\
- \\
$0.90 * * *$ \\
\hline
\end{tabular}

\begin{tabular}{c}
\hline ES \\
\hline-0.09 \\
0.18 \\
$0.25 *$ \\
$0.58 * * *$ \\
$0.91 * * *$ \\
$0.46 * * *$ \\
$0.90 * * *$ \\
-
\end{tabular}

A-3-S, androstenediol-3-sulfate; AS, androsterone sulfate; CS, cholesterol sulfate; DHEAS, dehydroepiandrosterone sulfate; ES, epiandrosterone sulfate; Pregs, pregnenolone sulfate. 
Table 3 Comparison of age, pubertal stage and steroid sulfates between boys and girls.

\begin{tabular}{l}
\hline Number \\
Age (years) \\
Prepubertal $(\%)$ \\
CS $(\mu \mathrm{M})$ \\
PregS $(\mu \mathrm{M})$ \\
$17 O H-P r e g S(\mu M)$ \\
$16 O H-D H E A S(\mu M)$ \\
DHEAS $(\mu M)$ \\
A-3-S $(\mu M)$ \\
AS $(\mu M)$ \\
ES $(\mu M)$
\end{tabular}

Boys
28
12 (IQR 10-13)
$17(61)$
1087 (IQR 882-1304)
35 (IQR 28-54)
5 (IQR 3-8)
78 (IQR 55-172)
875 (IQR 477-1080)
45 (IQR 26-58)
305 (IQR 200-392)
106 (IQR 67-149)

Girls
38
11 (IQR 8-13)
18 (47)
903 (IQR 704-1000)
25 (IQR 14-43)
4 (IQR 1-7)
76 (IQR 59-145)
551 (IQR 284-881)
25 (IQR 13-35)
433 (IQR 220-581)
152 (IQR 66-178)

\begin{tabular}{r}
\hline P-Value \\
\\
0.111 \\
0.151 \\
0.003 \\
0.049 \\
0.173 \\
0.989 \\
0.009 \\
$<0.001$ \\
0.111 \\
0.143
\end{tabular}

Data as median and interquartile range (IQR), $P$-value derived from Fisher exact test or Mann-Whitney $U$ test.

A-3-S, androstenediol-3-sulfate; AS, androsterone sulfate; CS, cholesterol sulfate; DHEAS, dehydroepiandrosterone sulfate; ES, epiandrosterone sulfate; Pregs, pregnenolone sulfate.

Changes of $17 \mathrm{OH}-$ PregS were significantly positively associated with changes of systolic BP $(\beta$-coefficient $0.059 \pm 0.04 ; P=0.013$ ) and changes of DHEAS were significantly negatively associated with changes of BMISDS ( $\beta$-coefficient $-150 \pm 109 ; P=0.008$ ), while no further significant associations could be observed in multiple linear regression analyses adjusted to age, gender, pubertal stage and changes of HOMA and changes of pubertal stage.

The children with and without substantial BMISDS reduction did not differ significantly according to age, gender, pubertal stage, cardiovascular risk factors or steroid sulfates at baseline except CS, which, as previously mentioned, was higher in children with BMI-SDS reduction.

Weight loss in 33 obese children (mean BMI-SDS $-0.75 \pm 0.25)$ was associated with significant decreases of HOMA, lipids and BP. In the obese 33 children with weight gain (mean change of BMI-SDS +0.25 \pm 0.17 ), triglycerides and systolic BP increased significantly, while all other cardiovascular risk factors did not change significantly (Table 5).

\section{Discussion}

To the best of our knowledge, this is the first study analyzing the longitudinal relationships of the sulfated steroidome in obese children participating in a lifestyle intervention. Our data show that concentrations of CS before intervention are higher in children who finally lost weight, which points to a higher capacity to sulfate cholesterol. This fact can be due to increased SULTs activity, to a decreased activity of sulfatases or to a combined effect of all enzymes.

The finding that children with higher CS concentrations loose more weight than those with lower CS concentrations are in line with the observation that obese girls with PCOS (a disease which has been reported to be associated with a disruption of sulfation $(15,16))$

Table 4 Comparison of steroid sulfates between prepubertal and pubertal children.

Number
Gender
CS $(\mu \mathrm{M})$
PregS $(\mu \mathrm{M})$
$170 \mathrm{H}-$ PregS $(\mu \mathrm{M})$
$16 \mathrm{OH}-\mathrm{DHEAS}(\mu \mathrm{M})$
DHEAS $(\mu \mathrm{M})$
A-3-S $(\mu \mathrm{M})$
AS $(\mu \mathrm{M})$
ES $(\mu \mathrm{M})$

\begin{tabular}{c}
\hline Prepubertal \\
35 \\
$17(49 \%)$ boys \\
945 (IQR 755-1149) \\
31 (IQR 17-41) \\
5 (IQR 2-6) \\
64 (IQR 37-100) \\
529 (IQR 299-789) \\
24 (IQR 14-41) \\
250 (IQR 165-393) \\
77 (IQR 57-142)
\end{tabular}

\begin{tabular}{c} 
Pubertal \\
\hline 31 \\
$11(35 \%)$ boys \\
939 (IQR 801-1211) \\
$29($ IQR 20-56) \\
5 (IQR 2-9) \\
95 (IQR 67-204) \\
901 (IQR 601-1160) \\
37 (IQR 25-53) \\
IQR 341-619) \\
160 (IQR 116-204)
\end{tabular}

\begin{tabular}{r}
\hline P-Value \\
\\
0.287 \\
0.782 \\
0.508 \\
0.407 \\
0.003 \\
0.002 \\
0.023 \\
$<0.001$ \\
$<0.001$
\end{tabular}

Data as median and interquartile range (IQR), $P$-value derived from Fisher exact test or Mann-Whitney $U$ test.

A-3-S, androstenediol-3-sulfate; AS, androsterone sulfate; CS, cholesterol sulfate; DHEAS, dehydroepiandrosterone sulfate; ES, epiandrosterone sulfate; Pregs, pregnenolone sulfate.

$\begin{array}{lr}\text { https://ec.bioscientifica.com } & \text { ○ } 2018 \text { The authors } \\ \text { https://doi.org/10.1530/EC-18-0233 } & \text { Published by Bioscientifica Ltd }\end{array}$

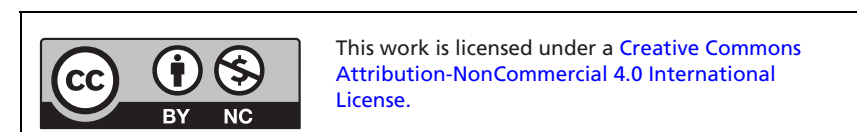




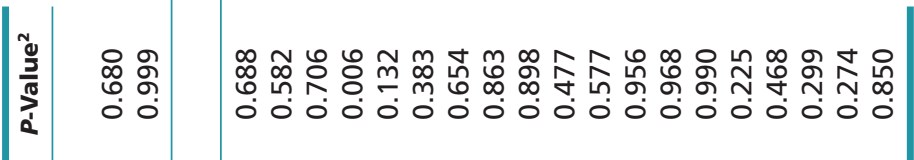

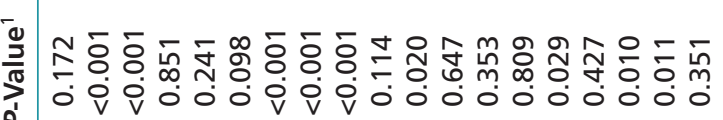

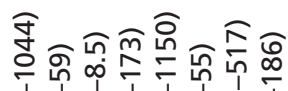

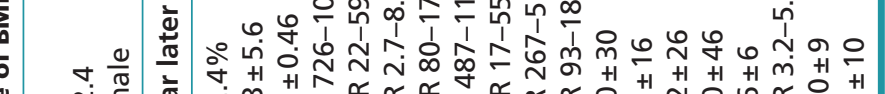

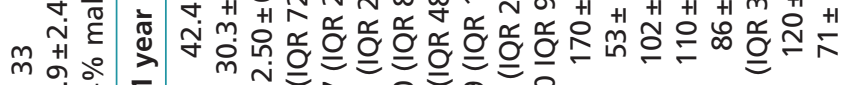

竞

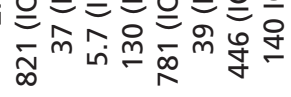

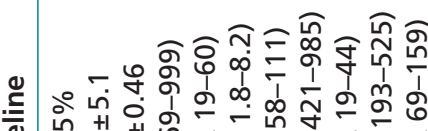

ลุ

ทे ก

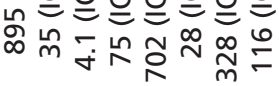

근

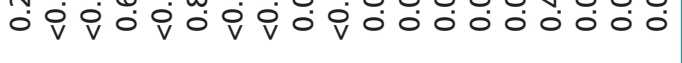

n

() 2018 The authors Published by Bioscientifica Ltd

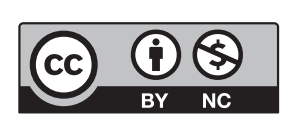

This work is licensed under a Creative Commons Attribution-NonCommercial 4.0 International License. 


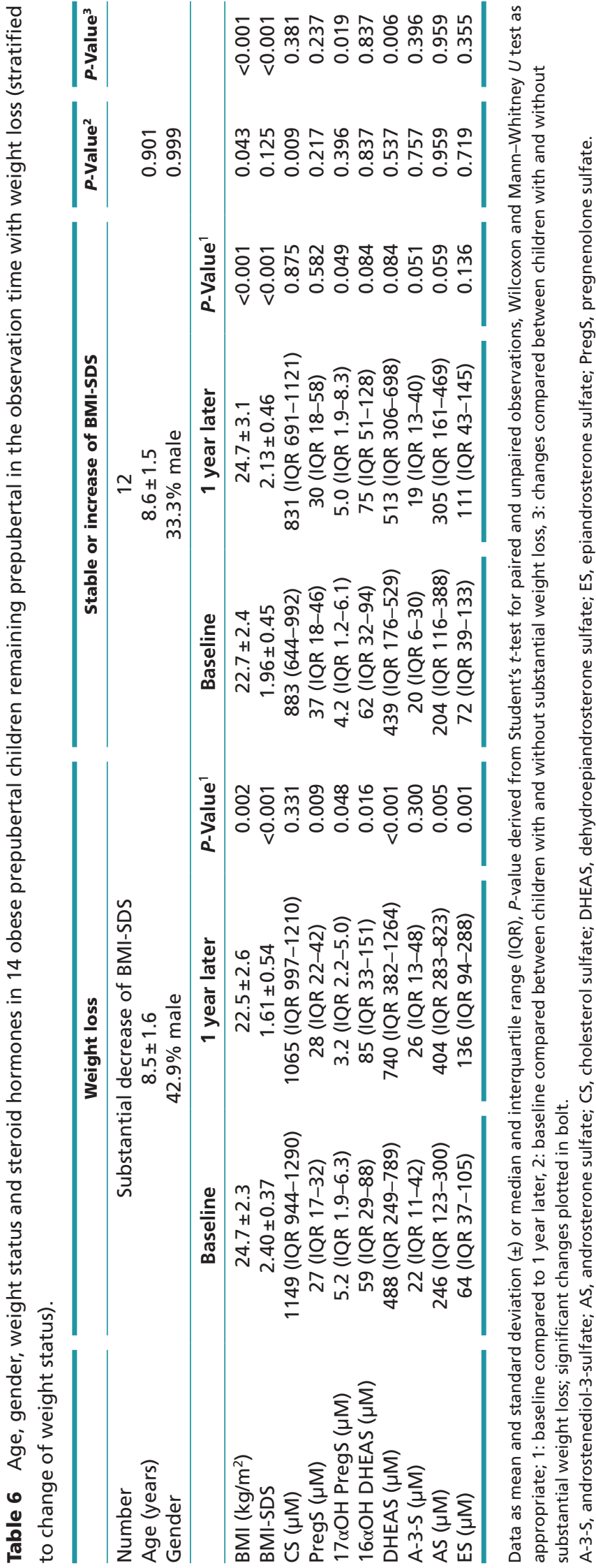

https://ec.bioscientifica.com https://doi.org/10.1530/EC-18-0233 have greater difficulties to lose weight compared to girls without PCOS (31). The underlying mechanisms are unclear so far and cannot be analyzed by our study. An impact of insulin resistance seems unlikely since CS was not related to HOMA in our study. Furthermore, it has been reported that CS and SULTs are important regulators of glucose metabolism inhibiting hepatic gluconeogenesis (32): In mice, CS alleviated insulin resistance and lowered the expression of liver gluconeogenic gene.

CS can also give rise to PregS - a key molecule to control steroidogenesis (33). Children who lost weight showed a significant rise in the concentration of this compound after 1 year, in contrast to children who did not lose weight. Higher concentrations of PregS decrease the amounts of free unconjugated pregnenolone, the starting metabolite for the synthesis of androgens and corticoids. Similarly, DHEAS increased more in children with substantial BMI-SDS reduction compared to children without BMI-SDS reduction in the 1-year observation period. Similarly, this decreases the availability of DHEA and has an impact on steroid biosynthesis. Such an effect can be clearly observed in STSD patients, with higher DHEAS concentrations but lower DHEA levels than controls $(19,34)$.

Therefore, our results pointing to a higher capacity to synthesize steroid sulfates in obese children with weight loss are coherent with previous reports in which substantial weight loss in obese children was associated with a decrease of unconjugated androgens or corticoids $(1,2,6)$. A general scheme for these ideas is depicted in Fig. 1.

The persistently elevated androgen sulfates after weight loss are in line with previous studies demonstrating elevated DHEAS after weight loss in long-term follow-up studies $(1,2)$. Our findings could suggest an irreversible maturation of the zona reticularis and the formation of sulfated androgens in obese children or shifted balance of STS and SULTs. Once the developmental path of adrenarche has been initiated, it continues irreversibly as reflected by the increasing sulfated androgen concentrations during the study period even after successful weight loss. We cannot decipher, however, whether obesity has been the first event which has only secondarily initiated exaggerated adrenarche or whether exaggerated adrenarche has actually been the first hit promoting development of obesity as the secondary event, which has also been suggested by others $(12,35)$. One potential mechanism explaining the increased levels of most sulfated steroids could be a lower activity of STS or of $3 \beta \mathrm{HSD} 2$, since $3 \beta \mathrm{HSD} 2$ could also have sulfatase

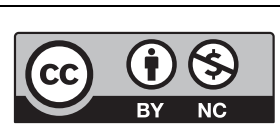

This work is licensed under a Creative Commons Attribution-NonCommercial 4.0 International License. 
Table 7 Associations between changes $(\Delta)$ of steroid sulfates and changes $(\Delta)$ of anthropometrics and cardiovascular risk factors at baseline (Spearman correlation).

\begin{tabular}{|c|c|c|c|c|c|c|c|c|}
\hline & $\Delta \mathrm{CS}$ & $\Delta$ PregS & $\begin{array}{c}\Delta 17 \alpha \mathrm{OH} \\
\text { PregS }\end{array}$ & $\begin{array}{l}\triangle 16 \alpha O H \\
\text { DHEAS }\end{array}$ & $\triangle$ DHEAS & $\Delta \mathbf{A}-\mathbf{3}-\mathbf{S}$ & $\Delta \mathbf{A S}$ & $\Delta E S$ \\
\hline$\triangle \mathrm{BMI}-\mathrm{SDS}$ & 0.11 & -0.16 & 0.17 & 0.07 & $-0.26 *$ & $0.026 *$ & -0.15 & -0.11 \\
\hline$\Delta$ Systolic blood pressure & 0.09 & 0.07 & $0.24 *$ & 0.07 & $-0.31 * *$ & 0.04 & -0.09 & -0.01 \\
\hline$\Delta$ Diastolic blood pressure & 0.16 & -0.14 & 0.03 & -0.10 & -0.19 & -0.02 & -0.14 & -0.09 \\
\hline$\Delta$ Fasting glucose & -0.13 & -0.11 & -0.07 & -0.16 & $-0.22 *$ & $-0.21 *$ & 0.02 & 0.02 \\
\hline$\triangle \mathrm{HOMA}$ & -0.04 & -0.01 & 0.04 & 0.05 & $-0.37 * * *$ & $0.22 *$ & -0.09 & 0.02 \\
\hline$\Delta$ Cholesterol & $0.36 * *$ & $-0.27^{\star}$ & -0.07 & $-0.33^{* *}$ & -0.18 & 0.03 & $-0.21 *$ & $-0.30^{* *}$ \\
\hline$\Delta \mathrm{HDL}$-cholesterol & 0.04 & -0.11 & -0.17 & 0.01 & 0.01 & 0.03 & $-0.21 *$ & $-0.30 * *$ \\
\hline$\Delta \mathrm{LDL}$-cholesterol & 0.22 & -0.18 & -0.23 & $-0.22 *$ & -0.19 & 0.04 & -0.04 & -0.11 \\
\hline$\Delta$ Triglycerides & 0.21 * & -0.07 & 0.08 & -0.11 & -0.16 & 0.11 & $-0.24 *$ & $-0.37^{\star *}$ \\
\hline
\end{tabular}

A-3-S, androstenediol-3-sulfate; AS, androsterone sulfate; CS, cholesterol sulfate; DHEAS, dehydroepiandrosterone sulfate; ES, epiandrosterone sulfate; HDL, high-density lipoprotein; LDL, low density lipoprotein; PregS, pregnenolone sulfate.

activity (19). Interestingly, adrenarche is accompanied by a lower expression of 3 $\beta$ HSD2 (36).

Except $17 \mathrm{OH}$-PregS, none of the sulfated androgens were associated to cardiovascular risk factors including insulin resistance. This finding is in contrast to unconjugated androgens, which are related to parameters of the metabolic syndrome $(2,5,6,7,8,9)$. However, systolic BP was significantly related to $17 \mathrm{OH}$-PregS both in cross-sectional and longitudinal analyses. Further studies are necessary to prove whether this relationship is relevant and to analyze the underlying mechanisms.

Most sulfated androgens and their precursors were higher in boys compared to girls, with the exception of AS, ES, 16OH-DHEAS and 17OH-PregS. We anticipated this difference previously for AS and ES based on the differences in STS activity between males and females (19). As previously described, DHEAS and CS had the highest concentrations of all analyzed steroid sulfates $(19,21)$. DHEAS and A-3-S production normally starts to increase at the age of 6-8 (adrenarche) and reaches its highest concentrations in blood at around 20-30 years of age in males and females $(37,38)$. The relationship between blood concentrations of sulfated steroids and age is well known (39). The increase of sulfated steroids with age could also be observed in our study, with the exception of CS, which showed similar levels in all children after one year of intervention. CS is the only measured sulfated steroid, which is not of adrenal origin and can be synthesized in other tissues (21).

Of interest, we found strong correlations between the concentrations of many sulfated steroids. These correlations are similar to the ones reported before in adult males (19). Synthesis of sulfated steroids is not only possible by a sulfation reaction of unconjugated steroids. Enzymatic conversion of some sulfated steroids into others is also a well-known physiological reaction. For instance, DHEAS can be converted into A-3-S, and PregS can be hydroxylated to produce $17 \mathrm{OH}-\mathrm{PregS}(33,40,41)$. As a consequence, steroid biosynthesis in humans is a complex set of interconnected pathways (19).

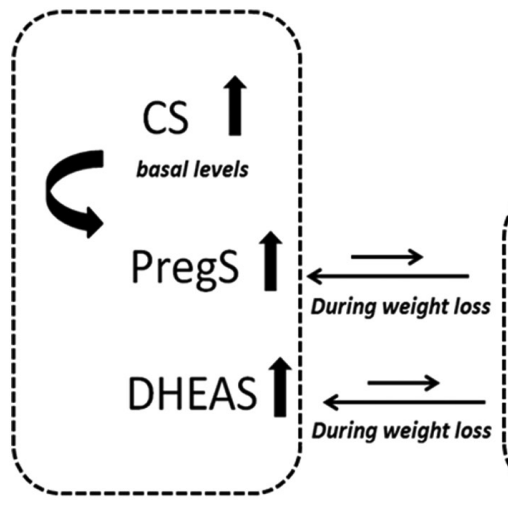

Sulfated steroids

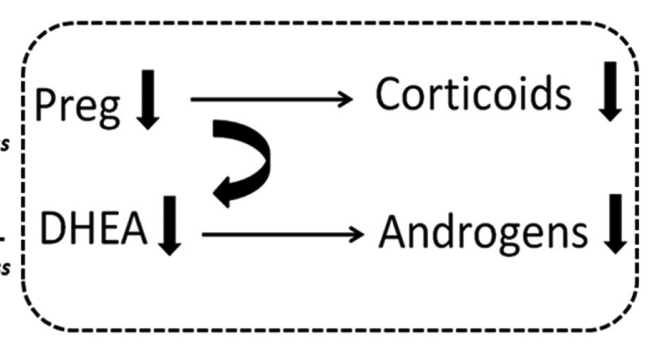

Unconjugated steroids
Figure 1

Overview of the steroidogenesis in obese children during weight loss. The increase of sulfated steroids affects the concentration of unconjugated steroid precursors and therefore of hormonal steroids. https://ec.bioscientifica.com

https://doi.org/10.1530/EC-18-0233 (c) 2018 The authors

Published by Bioscientifica Ltd

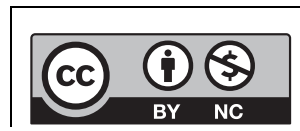

This work is licensed under a Creative Commons Attribution-NonCommercial 4.0 International License. 


\section{Strengths and limitations of the study}

The strengths of this study are its longitudinal design, the analyses of a comprehensive profile of intact steroid sulfates by state-of-the-art LC-MS/MS (21) and the study of a homogenous cohort of obese children naive to drugs. However, our study presents some potential limitations. First, BMI percentiles were used to classify overweight. Although BMI is a good measure for overweight, one needs to be aware of its limitations as an indirect measurement of fat mass. Second, we did not have a control group of normal weight children. Third, our study sample was too small to study gender differences on the changes of sulfated steroids in weight loss. Finally, weight loss may be too small to measure effects on sulfated steroids. On the other hand, a reduction of $\geq 0.5$ BMI-SDS, as achieved in our children with substantial weight loss, is reported to normalize many hormonal and metabolic changes in childhood obesity like insulin sensitivity, the cardiovascular risk factor profile, hormones including unconjugated androgens and adipocytokines (1, 2, 6, 23, 24).

In summary, most sulfated androgens and their precursors were higher in boys compared to girls. Furthermore, there is an increase in the levels of sulfated steroids, which can be associated to age in both groups, but in addition, children with weight loss showed higher capacity to sulfate steroids. This capacity was present before the intervention, with higher CS blood levels. Sulfated androgens were not related to cardiovascular risk factors except $17 \mathrm{OH}$-PregS, which was related to systolic BP. There is still a great need for further research on the alterations of sulfated steroids in obesity also to understand how the activity of enzymes related to the synthesis of these compounds, including SULTs, STS and probably $3 \beta \mathrm{HSD} 2$, can be altered in obesity. This study also points to the importance of quantifying sulfated steroids at different ages, in order to establish ranges for some compounds like CS and PregS. This could provide additional information previous to medical intervention in the treatment of obesity.

\section{Declaration of interest}

The authors declare that there is no conflict of interest that could be perceived as prejudicing the impartiality of the research reported.

\section{Funding}

The analytical part of this study was supported by the German Research Foundation (DFG) within DFG Research Group 1369 'Sulfated Steroids in Reproduction', subproject 7 'LC-MS/MS and GC-MS/MS based
Steroidomics' (SAW principal investigator, WU 148/6-2). The clinical part of this study received support from the Innovative Medicines Initiative Joint Undertaking under EMIF grant agreement $n^{\circ} 115372$, resources of which are composed of financial contribution from the European Union's Seventh Framework Programme (FP7/2007-2013) and EFPIA companies' in kind contribution. This manuscript does not necessarily reflect the views of the Commission and in no way anticipates the future policy in this area. Further grant support by the German Ministry of Education and Research (Obesity network: grant number $0101 \mathrm{GI} 1120 \mathrm{~A}, 01 \mathrm{GI} 1120 \mathrm{~B}$ and 001 GI 0825) is gratefully acknowledged. The funders had no role in study design, data collection and analysis, decision to publish, or preparation of the manuscript. This study is registered at clinicaltrials.gov (NCT00435734).

\section{Author contribution statement}

T R and S A W developed the study design, T R and N L performed the anthropometrical measurements and A S-G performed the laboratory measurements. All authors discussed the findings and participated in writing of the paper. T R and A S-G analyzed the data and wrote the first draft of the manuscript. T R, A S-G and S A W were the leading writers of the paper.

\section{Acknowledgment}

The authors thank the participating children.

\section{References}

1 Reinehr T, Kulle A, Wolters B, Lass N, Welzel M, Riepe F \& Holterhus P-M. Steroid hormone profiles in prepubertal obese children before and after weight loss. Journal of Clinical Endocrinology and Metabolism 201398 E1022-E1030. (https://doi.org/10.1210/ jc.2013-1173)

2 Reinehr T, de Sousa G, Roth CL \& Andler W. Androgens before and after weight loss in obese children. Journal of Clinical Endocrinology and Metabolism 200590 5588-5595. (https://doi.org/10.1210/ jc.2005-0438)

3 Samojlik E, Kirschner MA, Silber D, Schneider G \& Ertel NH. Elevated production and metabolic clearance rates of androgens in morbidly obese women. Journal of Clinical Endocrinology and Metabolism 1984 59 949-954. (https://doi.org/10.1210/jcem-59-5-949)

4 Gapstur SM, Gann PH, Kopp P, Colangelo L, Longcope C \& Liu K. Serum androgen concentrations in young men: a longitudinal analysis of associations with age, obesity, and race. The CARDIA male hormone study. Cancer Epidemiology, Biomarkers and Prevention 2002 11 1041-1047.

5 Bleicher M, Högel J, Wudy S, Wabitsch M, Homoki J, Sorgo W \& Heinze E. Insulin resistance (HOMA) in relation to plasma cortisol, IGF-I and IGFBP-3: a study in normal short-statured and GH-deficient children. Hormone Research 200258 229-232. (https:// doi.org/10.1159/000066266)

6 Reinehr T \& Andler W. Cortisol and its relation to insulin resistance before and after weight loss in obese children. Hormone Research 2004 62 107-112. (https://doi.org/10.1159/000079841)

7 De Sousa G, Brodoswki C, Kleber M, Wunsch R \& Reinehr T. Association between androgens, intima-media thickness and the metabolic syndrome in obese adolescent girls. Clinical Endocrinology 201072 770-774. (https://doi.org/10.1111/ j.1365-2265.2009.03710.x)

8 Hauner H, Ditschuneit HH, Pal SB, Moncayo R \& Pfeiffer EF. Fat distribution, endocrine and metabolic profile in obese women with and without hirsutism. Metabolism: Clinical and Experimental 1988 37 281-286. (https://doi.org/10.1016/0026-0495(88)90109-6)

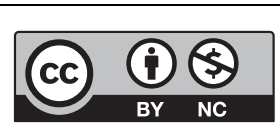

This work is licensed under a Creative Commons Attribution-NonCommercial 4.0 International License. 
9 Niskanen L, Laaksonen DE, Punnonen K, Mustajoki P, Kaukua J $\&$ Rissanen A. Changes in sex hormone-binding globulin and testosterone during weight loss and weight maintenance in abdominally obese men with the metabolic syndrome. Diabetes, Obesity and Metabolism 20046 208-215. (https://doi.org/10.1111/ j.1462-8902.2004.00335.x)

10 Ehrmann DA. Polycystic ovary syndrome. New England Journal of Medicine 20051 60-63.

11 l'Allemand D, Schmidt S, Rousson V, Brabant G, Gasser T \& Grüters A. Associations between body mass, leptin, IGF-I and circulating adrenal androgens in children with obesity and premature adrenarche. European Journal of Endocrinology 2002146 537-543. (https://doi.org/10.1530/eje.0.1460537)

12 Saenger P \& Dimartino-Nardi J. Premature adrenarche. Journal of Endocrinological Investigation 200124 724-733. (https://doi. org/10.1007/BF03343917)

13 Ma J, Yue J, Huang R, Liao Y, Li S \& Liu W. Reversion of agingrelated DHEAS decline in mouse plasma alleviates aging-related glucose tolerance impairment by potentiation of glucose-stimulated insulin secretion of acute phase. Biochemical and Biophysical Research Communications 2018500 671-675. (https://doi.org/10.1016/j. bbrc.2018.04.134)

14 Mueller JW, Gilligan LC, Idkowiak J, Arlt W \& Foster P. The regulation of steroid action by sulfation and desulfation. Endocrine Reviews 201536 526-563. (https://doi.org/10.1210/er.2015-1036)

15 Noordam C, Dhir V, McNelis JC, Schlereth F, Hanley NA, Krone N, Smeitink JA, Smeets R, Sweep FCGJ, Claahsen-van der Grinten HL, et al. Inactivating PAPSS2 mutations in a patient with premature pubarche. New England Journal of Medicine 2009360 2310-2318. (https://doi.org/10.1056/NEJMoa0810489)

16 Oostdijk W, Idkowiak J, Mueller JW, House PJ, Taylor AE, O'Reilly MW, Hughes BA, de Vries MC, Kant SG, Santen GWE, et al. PAPSS2 deficiency causes androgen excess via impaired DHEA sulfation - in vitro and in vivo studies in a family harboring two novel PAPSS2 mutations. Journal of Clinical Endocrinology and Metabolism 2015100 E672-E680. (https://doi.org/10.1210/jc.20143556)

17 Hobkirk R. Steroid sulfation current concepts. Trends in Endocrinology and Metabolism 19934 69-74. (https://doi.org/10.1016/S10432760(05)80018-9)

18 Geyer J, Bakhaus K, Bernhardt R, Blaschka C, Dezhkam Y, Fietz D, Grosser G, Hartmann K, Hartmann MF, Neunzig J, et al. The role of sulfated steroid hormones in reproductive processes. Journal of Steroid Biochemistry and Molecular Biology 2016172 207-221. (https://doi. org/10.1016/j.jsbmb.2016.07.002)

19 Sánchez-Guijo A, Neunzig J, Gerber A, Oji V, Hartmann MF, Schuppe H-C, Traupe H, Bernhardt R \& Wudy SA. Role of steroid sulfatase in steroid homeostasis and characterization of the sulfated steroid pathway: evidence from steroid sulfatase deficiency. Molecular and Cellular Endocrinology 2016437 142-153. (https://doi. org/10.1016/j.mce.2016.08.019)

20 Wudy SA, Schuler G, Sánchez-Guijo A \& Hartmann MF. The art of measuring steroids: principles and practice of current hormonal steroid analysis. Journal of Steroid Biochemistry and Molecular Biology 2017179 88-103. (https://doi.org/10.1016/j.jsbmb.2017.09.003)

21 Sánchez-Guijo A, Oji V, Hartmann MF, Traupe H \& Wudy SA. Simultaneous quantification of cholesterol sulfate, androgen sulfates, and progestagen sulfates in human serum by LC-MS/MS. Journal of Lipid Research 201556 1843-1851. (https://doi.org/10.1194/jlr. D061499)

22 Reinehr T, Roth C, Menke T \& Andler W. Adiponectin before and after weight loss in obese children. Journal of Clinical Endocrinology and Metabolism 200489 3790-3794. (https://doi.org/10.1210/ jc.2003-031925)

23 Reinehr T, Kratzsch J, Kiess W \& Andler W. Circulating soluble leptin receptor, leptin, and insulin resistance before and after weight loss in obese children. International Journal of Obesity 200529 1230-1235. (https://doi.org/10.1038/sj.ijo.0803027)

24 Reinehr T \& Andler W. Changes in the atherogenic risk factor profile according to degree of weight loss. Archives of Disease in Childhood 200489 419-422. (https://doi.org/10.1136/adc.2003.028803)

25 Reinehr T, de Sousa G, Toschke AM \& Andler W. Long-term follow-up of cardiovascular disease risk factors in children after an obesity intervention. American Journal of Clinical Nutrition $2006 \mathbf{8 4} 490-496$. (https://doi.org/10.1093/ajcn/84.3.490)

26 Cole TJ. The LMS method for constructing normalized growth standards. European Journal of Clinical Nutrition 199044 45-60.

27 Kromeyer-Hauschild K, Wabitsch M, Kunze D, Geller D, Geiss HC Hesse V, von Hippel A, Jaeger U, Johnsen D, Korte W, et al. Percentiles of body mass index in children and adolescents evaluated from different regional German studies. Monatsschrift Kinderheilkunde 2001149 807-818

28 Cole TJ, Bellizzi MC, Flegal KM \& Dietz WH. Establishing a standard definition for child overweight and obesity worldwide: international survey. BMJ 2000320 1240-1243. (https://doi.org/10.1136/ bmj.320.7244.1240)

29 National High Blood Pressure Education Program Working Group on High Blood Pressure in Children and Adolescents. The fourth report on the diagnosis, evaluation, and treatment of high blood pressure in children and adolescents. Pediatrics 2004114 555-576. (https:// doi.org/10.1542/peds.114.2.S2.555)

30 Matthews DR, Hosker JP, Rudenski S, Naylor B, Treacher DF \& Turner RC. Homeostasis model assessment: insulin resistance and beta-cell function from fasting plasma glucose and insulin concentrations in man. Diabetologia 198528 412-419. (https://doi. org/10.1007/BF00280883)

31 Lass N, Kleber M, Winkel K, Wunsch R \& Reinehr T. Effect of lifestyle intervention on features of polycystic ovarian syndrome, metabolic syndrome, and intima-media thickness in obese adolescent girls. Journal of Clinical Endocrinology and Metabolism 201196 3533-3540. (https://doi.org/10.1210/jc.2011-1609)

32 Shi X, Cheng Q, Xu L, Yan J, Jiang M, He J, Xu M, StefanovicRacic M, Sipula I, O’Doherty RM, et al. Cholesterol sulfate and cholesterol sulfotransferase inhibit gluconeogenesis by targeting hepatocyte nuclear factor $4 \alpha$. Molecular and Cellular Biology 201434 485-497. (https://doi.org/10.1128/MCB.01094-13)

33 Tuckey RC. Side-chain cleavage of cholesterol sulfate by ovarian mitochondria. Journal of Steroid Biochemistry and Molecular Biology 199037 121-127. (https://doi.org/10.1016/0960-0760(90)90380-4)

34 Idkowiak J, Taylor AE, Subtil S, O'Neil DM, Vijzelaar R, Dias RP, Amin R, Barrett TG, Shackleton CHL, Kirk JMW, et al. Steroid sulfatase deficiency and androgen activation before and after puberty. Journal of Clinical Endocrinology and Metabolism 2016101 2545-2553. (https://doi.org/10.1210/jc.2015-4101)

35 Pintor C, Loche S, Faedda A, Fanni V, Nurchi AM \& Corda R. Adrenal androgens in obese boys before and after weight loss. Hormone and Metabolic Research 198416 544-548. (https://doi. org/10.1055/s-2007-1014845)

36 Endoh A, Kristiansen SB, Casson PR, Buster JE \& Hornsby PJ. The zona reticularis is the site of biosynthesis of dehydroepiandrosterone and dehydroepiandrosterone sulfate in the adult human adrenal cortex resulting from its low expression of 3 beta-hydroxysteroid dehydrogenase. Journal of Clinical Endocrinology and Metabolism 199681 3558-3565. (https://doi.org/10.1210/jcem.81. $10.8855801)$

37 Šulcová J, Hill M, Hampl R \& Stárka L. Age and sex related differences in serum levels of unconjugated dehydroepiandrosterone and its sulphate in normal subjects. Journal of Endocrinology 1997154 57-62. (https://doi.org/10.1677/joe.0.1540057)

38 Rege J, Karashima S, Lerario AM, Smith JM, Auchus RJ, Kasa-Vubu JZ, Sasano H, Nakamura Y, White PC \& Rainey WE. Age-dependent increases in adrenal cytochrome B5 and serum 5-androstenediol-3-sulfate. https://ec.bioscientifica.com https://doi.org/10.1530/EC-18-0233 (c) 2018 The authors Published by Bioscientifica Ltd
This work is licensed under a Creative Commons Attribution-NonCommercial 4.0 International License. 
Journal of Clinical Endocrinology and Metabolism 2016101 4585-4593. (https://doi.org/10.1210/jc.2016-2864)

39 Rainey WE, Carr BR, Sasano H, Suzuki T \& Mason JI. Dissecting human adrenal androgen production. Trends in Endocrinology and Metabolism 200213 234-239. (https://doi.org/10.1016/S1043-2760 (02)00609-4)

40 Ruokonen A. Steroid metabolism in testis tissue: the metabolism of pregnenolone, pregnenolone sulfate, dehydroepiandrosterone and dehydroepiandrosterone sulfate in human and boar testes in vitro. Journal of Steroid Biochemistry 19789 939-946. (https://doi. org/10.1016/0022-4731(78)90054-7)

41 Neunzig J, Sánchez-Guijo A, Mosa A, Hartmann MF, Geyer J, Wudy SA \& Bernhardt R. A steroidogenic pathway for sulfonated steroids: the metabolism of pregnenolone sulfate. Journal of Steroid Biochemistry and Molecular Biology 2014144 324-333. (https://doi. org/10.1016/j.jsbmb.2014.07.005)

\section{Received in final form 6 August 2018}

Accepted 16 August 2018 https://ec.bioscientifica.com

https://doi.org/10.1530/EC-18-0233 (c) 2018 The authors Published by Bioscientifica Ltd

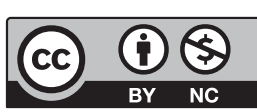

This work is licensed under a Creative Commons Attribution-NonCommercial 4.0 International License. 